\title{
ECONOMIC MODEL FOR CALCULATION OF DIRECT AND INDIRECT ECONOMICAL LOSSES FROM AFRICAN SWINE FEVER OCCURRENCE
}

\author{
P. IVANOVA ${ }^{1} \&$ E. IVANOVA ${ }^{2}$ \\ ${ }^{1}$ Bulgarian Food Safety Agency; ${ }^{2}$ National Diagnostic \& Research Veterinary \\ Medical Institute; Sofia, Bulgaria
}

\section{Summary}

Ivanova, P. \& E. Ivanova, 2019. Economic model for calculation of direct and indirect economical losses from African swine fever occurrence. Bulg. J. Vet. Med., 22, No 2, 227-236.

This study aimed to develop a model for calculation of direct and indirect economic losses in the event of African swine fever (ASF) occurrence. Calculation of the costs included the category of the affected holdings together with the specific biosecurity measures maintained therein and control measures to be imposed in the event of disease. Various scenarios for active and passive surveillance of the disease were developed, in order to prove the absence of virus circulation and to restore the status of the areas as ASF disease free-country.

Key words: African swine fever, alternative strategies, direct and indirect losses

\section{INTRODUCTION}

African swine fever (ASF) is one of the most complex and severe diseases occurring in pigs due to its high mortality, the lack of vaccine and last but not least, the immediate and long lasting trade bans imposed on the countries, in which it has occurred, which result in substantial agribusiness and economic losses.

So far, there is no vaccine developed to prevent the disease, therefore the old dictum saying that ,prevention is better than cure" could be fully applied to ASF. The control strategy against ASF must be based on the early detection of the disease and the prompt implementation of very strict measures for control and the best possible biosecurity of the pig holdings (Anonymous, 2006; 2009a,b; 2013).

\section{MATERIALS AND METHODS}

Estimates of losses in the event of an ASF outbreak were carried out by calculating both the financial and economic losses. The calculation of economic losses was done on the basis of the measures to be taken in the event of an outbreak, according to the current legislation, namely: the duration of epizootic, the total number of affected farms, the number of quarantine 
farms in the $3-\mathrm{km}$ protection zone and the $10-\mathrm{km}$ surveillance zone, the duration of the high-risk period and the number of herds that would be affected during this period. Data pertaining to the pig sector in the country over a period of 30 years were used (Petkov, 1985).

However, in calculating the costs we have taken into account the passive surveillance too, together with the expected willingness of farmers to report immediately in case of any suspicion of ASF outbreak, i. e. we have calculated the costs associated with raising the public awareness about ASF.

In order to calculate economic losses in case of an outbreak of the disease, the pig holdings were classified into four categories: farms of the backyard type (category 1); family farms of types A and B (category 2); pig holdings rearing EastBalkan pigs (category 3) and industrial pig farms (category 4).

A model to calculate the economic losses, which took into account the various epizootic scenarios (non-cash expenses for the impact of the disease) and direct cash costs related to the various measures imposed to ensure the eradication of this disease was developed. The indirect losses (ASF impact on the market in case of an outbreak occurrence) and any additional indirect losses (ASF influence on the market after an outbreak occurrence) were also calculated.

The direct and indirect losses were evaluated on the basis of information on prices of different categories of live animals officially published in the electronic newsletter of the National Statistical Institute (Anonymous, 2015) and other relevant data given in professional literature.

Economic losses (ELs) in case of ASF were a sum of direct costs (DCs) and the direct, incremental costs (DICs):

$$
\mathrm{ELs}=\mathrm{DCs}+\mathrm{DICs}
$$

The necessity from additional financial resources for proper implementation of active surveillance on ASF, in order to achieve reliable evidence of the absence of any ASFV circulation, hence restoration of the disease-free status of the respective territory (country) was also taken into account. For this purpose data from the annual financial reports on the implementation of the classical swine fever (CSF) active surveillance programme were used.

\section{RESULTS}

\section{Direct costs}

The calculation of direct costs (DCs) was done, taking into account the activities carried out in case of confirmed ASF outbreak in compliance with the current legislation.

Our personal experience with the eradication of infectious animal diseases in our country show that in order to cope with an epidemic, any service would face the necessity of extra funds for purchasing diagnostic kits for testing of samples, for compulsory slaughtering/culling of animals, for disposal of their carcasses, timely provision of adequate diagnostic teams of trained vets to perform clinical examinations, proper sampling, funds for extra fuel for the vehicles, for repair of equipment for disinfection and disinsection. This list of extra funds should also include the purchase of kits for sampling, provision of consumables, instrumentation and disposable garments; transportation costs to cover sending samples by courier companies to the National Reference Laboratory for ASF in Sofia; for sending positive samples for confirmation and serotyping to the EU Reference Labora- 
Table 1. Direct costs in case of occurrence of ASF in one pig holding

\begin{tabular}{|c|c|c|}
\hline Direct costs & Value (BGN) & Reference \\
\hline \multicolumn{3}{|l|}{ Costs for detecting and confirming an outbreak } \\
\hline Visit paid by a vet into a pig holding & $\begin{array}{c}30 \\
\text { (per one pig holding) }\end{array}$ & Anonymous, 2016 \\
\hline Consumables & 4 & \\
\hline Forwarding samples for laboratory confirmation & 20 & Häsler et al. (2012) \\
\hline Costs of laboratory testing / analysis & 3 & $\begin{array}{l}\text { Fernandez-Carrion } \\
\text { et al. }(2015)\end{array}$ \\
\hline Total & 57 & \\
\hline \multicolumn{3}{|l|}{ Costs related to implementation of control measures } \\
\hline $\begin{array}{l}\text { Imposing movement ban concerning the pig } \\
\text { holding affected (administrative costs, cost for } \\
\text { construction of disinfection ground, costs for } \\
\text { purchasing disinfecting agents, detergents and } \\
\text { others) }\end{array}$ & $\begin{array}{c}195 \\
\text { (per one pig holding) }\end{array}$ & $\begin{array}{l}\text { Fernandez-Carrion et } \\
\text { al. }(2015)\end{array}$ \\
\hline Euthanasia of animals using T61 & 5 & \\
\hline $\begin{array}{l}\text { Disposal of carcasses (incl. digging and backfill } \\
\text { activities, fencing, labour) }\end{array}$ & $\begin{array}{c}200 \\
\text { per one pig holding }\end{array}$ & Anonymous, 2011 \\
\hline $\begin{array}{l}\text { Cleaning and disinfecting (equipment, prepara- } \\
\text { tions, labour) }\end{array}$ & 1000 & Carpenter et al. (2011) \\
\hline Total & 1400 & \\
\hline \multicolumn{3}{|c|}{ Compensation paid to the owner of compulsory culled animal } \\
\hline $\begin{array}{l}\text { Sow } \\
\text { Fattened pig of } 80-110 \mathrm{~kg} \text { live weight } \\
\text { (over } 6 \text { months old) }\end{array}$ & $\begin{array}{c}300 \\
2.20 \mathrm{BGN} \\
\text { per kg live weight }\end{array}$ & Anonymous, 2015 \\
\hline $\begin{array}{l}\text { Young pigs of less than } 20 \mathrm{~kg} \text { live weight } \\
\text { (up to } 2 \text { months old) }\end{array}$ & $\begin{array}{l}\text { 3.80 BGN } \\
\text { per kg live weight }\end{array}$ & \\
\hline
\end{tabular}

tory for ASF in Spain; and other minor costs (marking signs, office supplies etc.). Detailed information about direct costs only per one holding is summarised in Table 1.

Knowing that at least 10 samples should be taken and tested from a farm in order to have valid confirmation of the disease, the direct costs of proving the disease in one animal (pig) holding $(\mathrm{PH})$ are $57 \mathrm{BGN}$, while the costs associated with eradication of ASF in 1 holding are on an average $1,500 \mathrm{BGN}+5 \mathrm{BGN}$ per each pig in that pig farm.

The cost of compensation paid to the owners of the dead and compulsory culled animals in the ASF affected farm would be 120 BGN per weaner, 240 BGN per fattened pig (ready for slaughtering) and 300 BGN per sow (Anonymous, 2015). 


\section{Direct, incremental costs (DICs)}

The direct, incremental costs were calculated for all pig farms located within the protection and surveillance zones around the ASF affected holding. These farms might be depopulated and remain empty within the 90 days (in case the animals are euthanised due to contact with the primary holding) or be operational (stocked with animals), but subject to the ban on movements of live animals and products thereof, if the latter have been produced within the previous 40 days (if respective holding is located within protection zone) or 30 days (if respective holding is located within the surveillance zone).

Direct, incremental costs (DICs) in empty (depopulated) pig farms

Empty (depopulated) farms suffer losses related to the possible production factors. Assuming that the farm $i$ produces an average daily output equal to the total number of pigs $-n C B(i)$ - divided by the length of one production cycle $(l)$, then production factors of this farm could be calculated by using the following formula:

$$
L(i)=\frac{90 \times n C B(i) \times V}{l}
$$

where $V$ is the price at which farmers sell a pig in the end of the production cycle.

Given that a pig before slaughter weighs about $110 \mathrm{~kg}$ and that its wholesale price is about 2.20 BGN per kg live weight, then one fattened pig would cost about 240 BGN. A weaner for fattening weighs on the average about 30 to $40 \mathrm{~kg}$, then the sale of such an animal to a farm for further fattening would bring to its owner about $4 \mathrm{BGN}$ per $\mathrm{kg}$ live weight or about 120-160 BGN per weaner.

The duration of one production cycle for further fattening is about 90 days.
Calculation of direct, incremental costs (DICs) in populated pig farms

Holdings that are populated with animals suffer losses, due to the bans imposed on movement of live pigs coming from such farms. Actually, category 1 farms (i.e. the backyard farms) are not affected by this type of losses, because animals in them are not sold as they are intended for personal consumption only. The farms where pigs are fattened for slaughter (of categories 3 and 4) are affected by such ban on movements, since it results in excessive increase of the weight of the pigs, which in turn reduces their sale price.

A pig weighing about $110 \mathrm{~kg}$ intended for slaughter has a selling price of about 240 BGN. The average daily intake of a pig for fattening is $2.5 \mathrm{~kg}$ compound feed. By 08.10 .2015 , the average price of such compound feed was $0.57 \mathrm{BGN} / \mathrm{kg}$ (from 0.52 to $0.60 \mathrm{BGN} / \mathrm{kg}$ ). The compound feed needed by one pig for a period of 30 40 days is about $100 \mathrm{~kg}$, thus one pig of this age group would then consume feed for approximately $57 \mathrm{BGN}(100 \mathrm{~kg} \times 0.57$ $\mathrm{BGN} / \mathrm{kg}$ ). One pig for fattening has an average daily gain of $0.650 \mathrm{~g}$, i.e. the weight to be gained for the period of restrictions would be about $25-30 \mathrm{~kg}$.

If such an animal has to be grown for another 30 or 40 days on this farm, it would increase its weight by up to 135 $140 \mathrm{~kg}$, but its selling price would then be about $1.60 \mathrm{BGN} / \mathrm{kg}$ live weight, i.e. about 220 BGN. The owner's costs for raising one animal for this extended period of 30 40 days would be about 60 BGN.

Based on these data, we have calculated the losses born by such farmers that have to suffer the imposed burden of ASF restrictions per one fattening pig would be [240-(220-60)] / $2=40 \mathrm{BGN}$ for the whole time period of effective ban imposed due to an ASF outbreak. 
Family farms of Type A (category 2) do not sell weaned pigs for fattening and hence those animals remain in these farms for the entire production cycle, within which movement ban is imposed. In this case, the losses suffered by the owner of those animals actually include either the cost of the feed or the cost of culling the new-born piglets. Furthermore, the lack of place for accommodation of weaned piglets results in overpopulation of the holding. The fact that the price of a pig for fattening weighing more than $50 \mathrm{~kg}$ was significantly lower $(2.20 \mathrm{BGN} / \mathrm{kg}$ live weight) should be also taken into account.

The average daily intake of a weaner (growing pig) is $1.9 \mathrm{~kg}(1.8-2.0 \mathrm{~kg})$ compound feed. As of 08 January 2015, the average price of compound feed for weaners was $0.61 \mathrm{BGN} / \mathrm{kg}$. The total amount needed by one animal for a period of 30-40 days is $75 \mathrm{~kg}$ compound feed. The total feed to be consumed by a pig of this age group would then cost about 45 BGN $(75 \mathrm{~kg} \times 0.61 \mathrm{BGN} / \mathrm{kg})$. A weaner has an average daily growth rate of about $0.390 \mathrm{~g}$ (0.330 to $0.450 \mathrm{~g})$, i.e. the weight that would be gained for the period of restrictions would be about $15-20 \mathrm{~kg}$. Thus, losses that would be incurred by farmer rearing animals in a holding of Category 2 should be $[120$ - (115-45)] / 2 $=25 \mathrm{BGN}$ for each growing pig. Knowing that a sow gives birth to an average of 10 piglets in one litter, the loss related to the offspring of one sow would be $250 \mathrm{BGN}$.

All the parameters used by us to develop this economic model have been collected by using the expert opinion of leading experts in the pig sector, together with relevant data from the specialised literature (Table 2).

\section{Losses summary}

Direct losses from direct costs. Based on the parameters used for calculating direct costs, it was concluded that direct losses of one pig holding would be 1,557 BGN + 5 BGN per each pig. As for the additional (incremental) losses for compensation these are 120 BGN per growing up pig, 240 BGN per fattening pig ready for slaughtering and $300 \mathrm{BGN}$ per sow. These are valid for any pig holding category.

Table 2. Parameters used in the model for calculation of economic losses

\begin{tabular}{|c|c|}
\hline \multicolumn{2}{|l|}{ Parameter } \\
\hline Duration of the period of suckling & 24 days (21-28 days) \\
\hline Duration of the grow up period & 55 days (50-60 days) \\
\hline Duration of the fattening period & 90 days ( $80-100$ days) \\
\hline Number of piglets in one litter & $10(8-12)$ \\
\hline Normal live weight of a ready-to-be-slaughtered pig & $110 \mathrm{~kg}$ \\
\hline Price of $\mathrm{kg}$ live weight of pigs weighing between 80 and $110 \mathrm{~kg}$ & 2.20 BGN per kg live weight \\
\hline $\begin{array}{l}\text { Further growing of the fattening pigs for the period of restric- } \\
\text { tions (ban) }\end{array}$ & by $26 \mathrm{~kg}$ \\
\hline Price of $1 \mathrm{~kg}$ live weight of the pigs weighing more than $110 \mathrm{~kg}$ & 1.60 BGN per kg live weight \\
\hline Additional feed costs per one pig subject to fattening & $57 \mathrm{BGN}$ \\
\hline Weight of a growing up pig & $30 \mathrm{~kg}$ \\
\hline Price of $1 \mathrm{~kg}$ live weight of pigs weighing up to $50 \mathrm{~kg}$ & 4.00 BGN per kg live weight \\
\hline Weight growth of pigs within the period of restrictions (ban) & $15-20 \mathrm{~kg}$ \\
\hline Price of $1 \mathrm{~kg}$ live weight of pigs weighing over $50 \mathrm{~kg}$ & 2.20 BGN per kg live weight \\
\hline Additional feed costs for one growing up pig & $45 \mathrm{BGN}$ \\
\hline
\end{tabular}


Indirect losses from direct, incremental costs. Direct, incremental costs for farms located within protection and surveillance zones around the outbreak amount to 250 BGN per one sow of a category 2 holding while for categories 3 and 4 holdings these are 40 BGN per one fattening pig, and insignificant for category 1 farms.

Based on our economic model we can calculate the economic losses (ELs) from the following scenario:

ASF is been detected at an industrial farm housing 250 sows, 1,000 grower-ups and 1,000 fattening pigs. Within the $3-\mathrm{km}$ protection zone around the outbreak there are 10 category 1 pig holdings and one category 2 pig holding of with 5 sows. In the $10-\mathrm{km}$ surveillance zone there is one category 3 holding of housing 100 East Balkan pigs.

According to the developed economic model, economic losses under this scenario are calculated as a sum of direct costs and direct, incremental costs (Table 3) The total economic losses in case of detection of ASF in one holding only are $452,957 \mathrm{BGN}$.

At the same time indirect, incremental costs related to the ban on trade and the drop of prices of goods; commercial losses due to non-compliance with signed contracts; production losses outside the agriculture sector; losses for farmers - the difference between the amounts paid for compensations and the real market value should also be taken into consideration.

\section{Costs for alternative strategies}

The alternative strategies for control of ASF are aimed at early detection of the disease and increased rate of notification in case of suspicion. The activities that should be covered by alternative strategies should include awareness campaigns for all stakeholders - veterinary professionals, farmers, hunters, local authorities and the public about ASF and the threats it poses; training of veterinary experts on ASF and practical aspects of its early detection, control and eradication.

Calculation of the costs for alternative strategies was made on the basis of organisation of and participation in a twoday seminar for all the 28 administrative districts of the country (around 100 participants in a workshop). Taking into account transportation costs, living accommodations, lecture fees, rental hall, etc., the participation of one person would cost

Table 3. Data on economic losses under the scenario considered by us

\begin{tabular}{lrrr}
\hline Parameter & Number & Unit price & \multicolumn{1}{c}{ Total } \\
\hline Costs for detecting an outbreak & & & 57 \\
Costs for other activities & 2,250 & 5 & 1,400 \\
Euthtanasia of the animals in the farm & 250 & 300 & 11,250 \\
Compensation payable per one sow & 1,000 & 120 & 75,000 \\
Growing up pigs & 1,000 & 240 & 120,000 \\
Pigs for fattenning & & & 240,000 \\
\hline Total direct costs & 5 & 250 & 447,707 \\
\hline Category 2 AH within the 3-km zone & 100 & 40 & 1,250 \\
Category 2 AH within the 10-km zone & & & 5,000 \\
\hline Total direct, incremental costs & & & 5,250 \\
\hline Total economic losses & & & 452,957 \\
\hline
\end{tabular}


Table 4. Summarising the costs for development of alternative strategy for control of ASF

\begin{tabular}{llc}
\hline Parameter & \multicolumn{1}{c}{ Units } & Value (BGN) \\
\hline $\begin{array}{l}\text { Organising and performing a } \\
\text { two-day training seminar }\end{array}$ & 2,800 & 28,000 \\
$\begin{array}{l}\text { Development and printing of } \\
\text { informative brochures }\end{array}$ & 100,000 copies & 1,500 \\
\hline Total & & 29,500 \\
\hline
\end{tabular}

Table 5. Number of samples to be taken for ASF testing from the various categories of pig holdings within one year.

\begin{tabular}{lccc}
\hline Holding type & $\begin{array}{c}\text { Total number of } \\
\text { animals }\end{array}$ & $\begin{array}{c}\text { Number of animals } \\
\text { within the } \\
\text { programme }\end{array}$ & $\begin{array}{c}\text { Number of animals } \\
\text { expected to be tested }\end{array}$ \\
\hline Industrial farms & 424,139 & 424,139 & 728 \\
Family farms of type A & 37,518 & 37,518 & 1,638 \\
Family farms of type B & 8,468 & 8,468 & 4,510 \\
Backyard farms & 41,843 & 41,843 & - \\
East-Balkan pigs' farms & 5,773 & 5,773 & 7,738 \\
\hline Total & 517,741 & 517,741 & \\
\hline
\end{tabular}

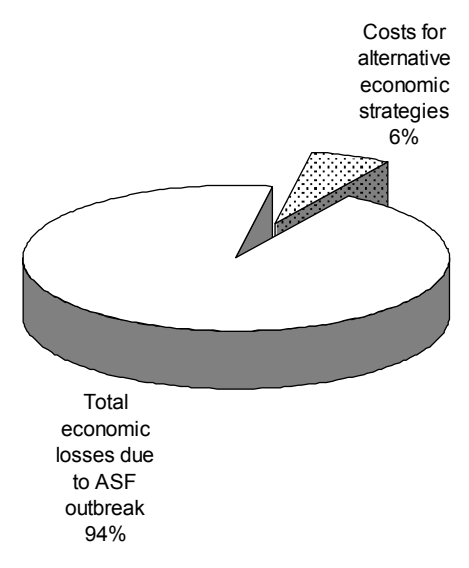

Fig. 1. Share of costs for developing and effecting an alternative economic strategy and all estimated losses under the developed scenario.

around $100 \mathrm{BGN}$. In addition to the training seminars, developing, printing and distribution o brochures and leaflets with relevant information developed to stakeholders would be useful.

With regard to the importance of improving the country's readiness, the costs of developing a lasting and feasible alternative strategy to improve the readiness of the country at the various levels were estimated to about 29,500 BGN (Table 4).

The share of the costs of developing and implementing an alternative strategy is only $6 \%$ of the estimated economic losses within the aforementioned scenario (Fig. 1). Therefore, the costs of raising the awareness at all levels are insignificant, understanding all benefits they might contribute.

Costs for restoration of statute of $A S F$-free (disease-free) country

In addition to direct and indirect losses for the pig-producing sector that will occur within an ASF event of disease ASF, it is also necessary to provide funds to restore 
Economic model for calculation of direct and indirect economical losses from African swine fever....

Table 6. Financial resources necessary for active surveillance of ASF

\begin{tabular}{lccc}
\hline Activity & Number & $\begin{array}{c}\text { Unit price } \\
(\mathrm{BGN})\end{array}$ & Total \\
\hline $\begin{array}{l}\text { Laboratory diagnostics } \\
\begin{array}{l}\text { ELISA test for antibodies } \\
\text { Sampling (including transportation } \\
\text { costs and consumables) }\end{array}\end{array}$ & 7,738 & 3.00 & 23,214 \\
\hline Total & 7,738 & 2.00 & 15,476 \\
\hline
\end{tabular}

the country's statute of a ASF-free country to the World Organisation for Animal Health (OIE).

In order to prove the lack of circulation of the ASF virus serological surveillance should be carried out to detect $20 \%$ prevalence with $95 \%$ confidence limits taking into consideration the average number of pigs kept in the different categories of pig farms present in the country. Samples for laboratory testing of pigs reared into backyard farms are taken, only if changes in the health status of the pigs are found. Table 5 provides information on the necessary number of samples to be taken within one year from the various pig holdings categories. In order to have reliable evidence of the lack of circulation of ASF virus, 38,690 BGN should be needed on a yearly basis (Table 6).

Restoration of the disease-free statute of the country might take years. Furthermore, in the event of an ASF outbreak in countries, which have been free from the disease, international trade restrictions lasting from several months to several years are imposed, which incur additional losses for the affected country.

\section{DISCUSSION}

With the increasing integration of international markets, it is extremely important that national policies would be appropri- ately coordinated for control of infectious animal diseases, such as ASF. Economical solutions are essential in developing measures to evaluate and manage the risk of occurrence of ASF.

Performing adequate socio-economic analysis (including calculation of direct and indirect losses due to the occurrence of ASF, its impact on livestock sector, and analysis of sectoral strategies) may be a useful tool in developing a programme for prevention and control of ASF with the objective of introducing an effective strategy to serve the government in planning activities for prevention and control. Any lack of financial resources creates real danger of rapid spread of the disease among the population of susceptible animals not only on our territory, but also in neighbouring countries and throughout the European Union. Furthermore, there is real danger that the European Commission starts an infringement procedure against our country, if our commitments as an EU member state to ensure rapid containment and eradication of the disease are not fulfilled.

Analysis of this economic model highlights the benefits of a programme based on economic parameters, namely:

- decreased risk of spread of ASF in the European Union;

- possibility for Bulgarian farmers to gain access to European markets;

- opportunity for producers of pork and 
pork products to participate in the free trade within the EU and to third countries;

- eradication of AFS within the feral pig population, the latter been the main reservoir of ASF virus, thus reducing substantially the risk for its transmission to the East-Balkan pigs population.

In view of the limited resources that the government can spend, the funding eligible within the Structural Funds, in particular those within the European Social Fund should be effectively used. It will be necessary to have an even closer focusing and targeting of funds according to well justified priorities.

As stated by Saatkamp et al. (2014), economic losses in case of ASF have been focused on direct costs (costs related to the implementation of measures to control and eradicate the disease) and direct, incremental (additional) costs (the costs related to prevention of further spread of ASF virus).

Considering the devastating impact of some diseases (incl. ASF) on producers, consumers, the economy and society as a whole, the national strategy must place the emphasis rather on preventive precautions, surveillance and on all capable measures to reduce the risk of occurrence and further spread of such diseases, than on the eradication of their consequences.

Just for comparison, we should point out that, according to Russian veterinary authorities, the overall economic losses due to the ASF epidemics within the period between 2007-2011, have reached 300 billion Russian roubles (about one billion US dollars); more than 600,000 pigs were culled and disposed in the course of the efforts to eradicate ASF in the Russian Federation (Nepoklonov, 2011).
As affirmed by Ivanov (2014), the Bulgarian Food Safety Agency should consider the option enabling the system for compensation payable to owners to be based on categorisation of animal diseases, combined with incentives for risk prevention, focusing more on incentives rather than penalties.

The calculation of direct and indirect economic losses in case of ASF in Bulgaria unequivocally proves the "Prevention is better than cure" EU strategy.

The main objective should be to achieve the best possible legal framework for prevention and control of animal diseases in Bulgaria, but also to have improvements in coherence between the Community policy on animal health and welfare and compliance with the rules on protection of animal welfare, and the rules on safety of food and feed, from one side) and all the other EU policies, from the other side, knowing well all the international commitments signed by our country. This main objective will be leading within the development of new policies or guidelines and will enhance existing measures to protect animal health, based on scientific risk assessments of risks and taking into account all social, economic and ethical considerations and relevant impacts on the environment. It will also support the achievement of a higher level of protection of the environment and biodiversity.

\section{ACKNOWLEDGEMENTS}

Our sincere thanks to Prof. Dr. Mihni Lyutskanov (Trakia University, Bulgaria), team of ASFORCE Project and the experts from the Animal Health Department, Bulgarian Food Safety Agency. 


\section{REFERENCES}

Anonymous, 2006. Ordinance No 102 of 21.08.2006 on the prevention, control and eradication of African swine fever, transposing Directive 2002/60/EC on Community measures for control of ASF;

Anonymous, 2009a. National Veterinary Service (NVS): Operational (Contingency) Plan on eradication of certain particularly topical infectious animal diseases in Bulgaria, approved by an Order of the NVS Director General (ref. No RD 11754/20.07.2009);

Anonymous, 2009b. National Veterinary Service (NVS): Practical Guide for control of ASF approved by NVS Director General's Order (ref. No RD 11-754/20.07.2009)

Anonymous, 2011. Financial report on the implementation of ASF control and eradication programme in the Republic of Bulgaria in $2011(\mathrm{BG})$

Anonymous, 2013. Ordinance No 6 on the terms applicable to rearing of East-Balkan pigs and their crossbreds. (Promulgated in State Gazette No 90 of 15.10.2013);

Anonymous, 2015. National Statistical Institute (NSI) Newsletter: Prices of agricultural products for 2015;

Anonymous, 2016. Tariff for setting the prices to be paid for the implementation of measures under the program for the prevention, control, eradication and eradication of animal diseases and zoonoses (State Gazette, 30 of 15.04.2016).

Carpenter, T. E., J. M. O’Brien, A. D. Hagerman \& B. A. McCarl, 2011. Epidemic and economic impacts of delayed detection of foot-and-mouth disease: a case study of a simulated outbreak in California. Journal of Veterinary Diagnostic Investigation, 23, 26-33.

Fernandez-Carrion, E., B. Ivorra, B. MartinezLopez, A. R. Ramos \& J. M. Sanchez-
Vizcaino, 2015. Implementation and validation of an economic module for the epidemiological model Be-FAST to predict the costs generated by livestock diseases epidemics. Preventive Veterinary Medicine, doi: 10.1016/j.prevetmed.2016.01.015.

Häsler, B., K. S. Howe, E. Di Labio, H. Schwermer \& K. D. C. Stärk, 2012. Economic evaluation of the surveillance and intervention programme for bluetongue virus serotype 8 in Switzerland. Preventive Veterinary Medicine, 103, 93-111.

Ivanov, Y., 2014. Strategy of the Bulgarian Food Safety Agency for 2014-2020 (BG).

Nepoklonov, E., 2011. Eradication of ASF exchange of good practices: Encountered problems and way to overcome them. Presentation at the ASF Global Alliance workshop, 26-29.09.2011, Rome.

Petkov, P., 1985. Biogeochemical studies and endemic diseases in Camborough pig hybrids. PhD Thesis, Faculty of Veterinary Medicine, Stara Zagora, Bulgaria.

Saatkamp, H. W., M. C. Mourits \& K. S. Howe, 2014. A framework for categorization of the economic impacts of outbreaks of highly contagious livestock diseases. Transboundary and Emerging Diseases, 63, 422-434.

Paper received 17.03.2017; accepted for publication 05.06.2017

\section{Correspondence:}

Dr. Petya Petkova Ivanova (DVM, PhD)

Deputy Executive Director/ Deputy CVO

Bulgarian Food Safety Agency

15A Pencho Slaveikov blvd

1606 Sofia, Bulgaria

tel.: 0035929159830

e-mail: p_petkova@bfsa.bg 